\title{
Effects of rejuvenation on cutting propagation of Mediterranean shrub species
}

\author{
Pignatti G* (1), Crobeddu S ${ }^{(2)}$
}

(1) Istituto Sperimentale per la Meccanizzazione Agricola, Consiglio per la Ricerca e Sperimentazione in Agricoltura (CRA), via della Pascolare 16, 00016 Monterotondo (Roma), Italy; (2) Istituto di Sperimentazione per la Pioppicoltura, CRA, Via Valle della Quistione 27, 00166 Roma, Italy. - *corresponding author: giuseppe.pignatti@entecra.it

\begin{abstract}
Two tests (April and August) on cutting propagation of seven Mediterranean shrub species (Arbutus unedo, Laurus nobilis, Myrtus communis, Olea europaea var. sylvestris, Phillyrea latifolia, Pistacia lentiscus and Viburnum tinus) were carried out to compare rooting percentage of cuttings from shoots of mature plants with those from rejuvenated plants (1.5-year rooted cuttings). Best rooting percentages were obtained by rejuvenated material. Rejuvenated Laurus nobilis, Myrtus communis, Olea europaea, Phillyrea latifolia and Viburnum tinus exhibited rooting percentages higher than 50\%, whereas for Arbutus unedo, and Pistacia lentiscus the percentages were lower.
\end{abstract}

Keywords: Cutting propagation, Juvenility, Mediterranean shrubs.

Received: Mar 10, 2005 - Accepted: Jul 18, 2005

Citation: Pignatti G, Crobeddu S, 2005. Effects of rejuvenation on cutting propagation of Mediterranean shrub species. Forest@ 2 (3): 290-295. [online] URL: http://www.sisef.it/

\section{Introduction}

Several Mediterranean shrub species can be propagated asexually by cuttings and in vitro propagation is possible for some species (Morini \& Fiaschi 2000, Nobre et al. 2000, Frau et al. 2001, Mereti et al. 2002). However, in small nurseries with limited equipment, in vivo vegetative propagation practices are still a sensible choice.

Studies carried out on ornamental shrub species investigated the effect of different rooting factors, such as growth regulators or other treatments, that could improve the rooting probability of cuttings, with the objective of developing mass propagation protocols for nurseries (Morini et al. 2003, Frangi \& Nicola 2004, La Viola et al. 2004). However, for some critical species the rooting probability remained too low to guarantee commercial interest.

In difficult-to-root species, rooting of cuttings can be improved by rejuvenation, i.e. by transition from the mature to the juvenile form of a plant (Greenwood 1987, Hartmann et al. 2002). There are several manipulation techniques which growers use to retain juvenility (hedging, cutting plants back to the base and growth regulators applications) or to induce it (successive grafting, chemical manipulation or micropropagation). For example, in Eucalyptus $x$ trabutii rejuvenation was obtained with serial grafting of mature forms (scion) onto seedling rootstock (Siniscalco \& Pavolettoni 1988).

So far, comprehensive studies on the role of rejuvenation for the propagation of Mediterranean species are lacking. In this preliminary study we investigated the effect of a method of rejuvenation and of the period of planting on the rooting probability of cuttings from seven Mediterranean species of major importance for commercial nurseries. The aim of the paper is to describe the main findings and to discuss the development of further research on this topic. Our hypothesis is that rejuvenated material for cuttings could increase the propagation success of some Mediterranean shrub species significantly, yielding success rates that guarantee a commercial interest.

\section{Materials and methods}

The following species were selected for the study: Arbutus unedo L., Laurus nobilis L., Myrtus communis 
L., Olea europaea L.var. sylvestris Brot., Phillyrea latifolia L., Pistacia lentiscus L. and Viburnum tinus L. These represent natural components of the Mediterranean maquis, but have also a relevance as ornamentals, i.e. for cut foliage production (Cervelli \& De Lucia 2004), or for restoration ecology purposes (Deidda \& Mulas 2004).

Approximately 20-year mature donor plants, grown in the open of a nursery in Rome, were used in spring (April 2004) for collecting semi-hardwood cuttings (named " $\mathrm{M}$ "). These were obtained from new shoots emerging at branches which were pruned in the winter. In the same period other material was collected from previously rooted cuttings (juvenile donor plants, named "J"). This rejuvenation method, described by Davies (1983) as "serial cutting", was used with some success for the difficultto-root cuttings of Quercus virginiana (Morgan et al. 1980). The juvenile donor plants (fig. 1), grown in an unheated glasshouse, were 1.5 years old and were frequently pruned to stimulate the emergence of new semi-hardwood shoots. A second test was carried out in mid-summer (August 2004) with the same materials.

For each species and type of material, 48 cuttings (fig. 2) were planted in alveolar containers filled with propagation medium (peat and perlite 1:1 v/v) and placed in enclosed frames covered with polyethylene. Basal heating (minimum temperature $19^{\circ} \mathrm{C}$ ) and mist irrigation were provided. Cuttings were treated with $0.8 \% \quad \alpha$-naphtalene acetic acid (NAA) in powder formulation. NAA and IBA (indole 3-butyric acid) are synthetic growth regulators, which belong to the class of auxins. It has been re-

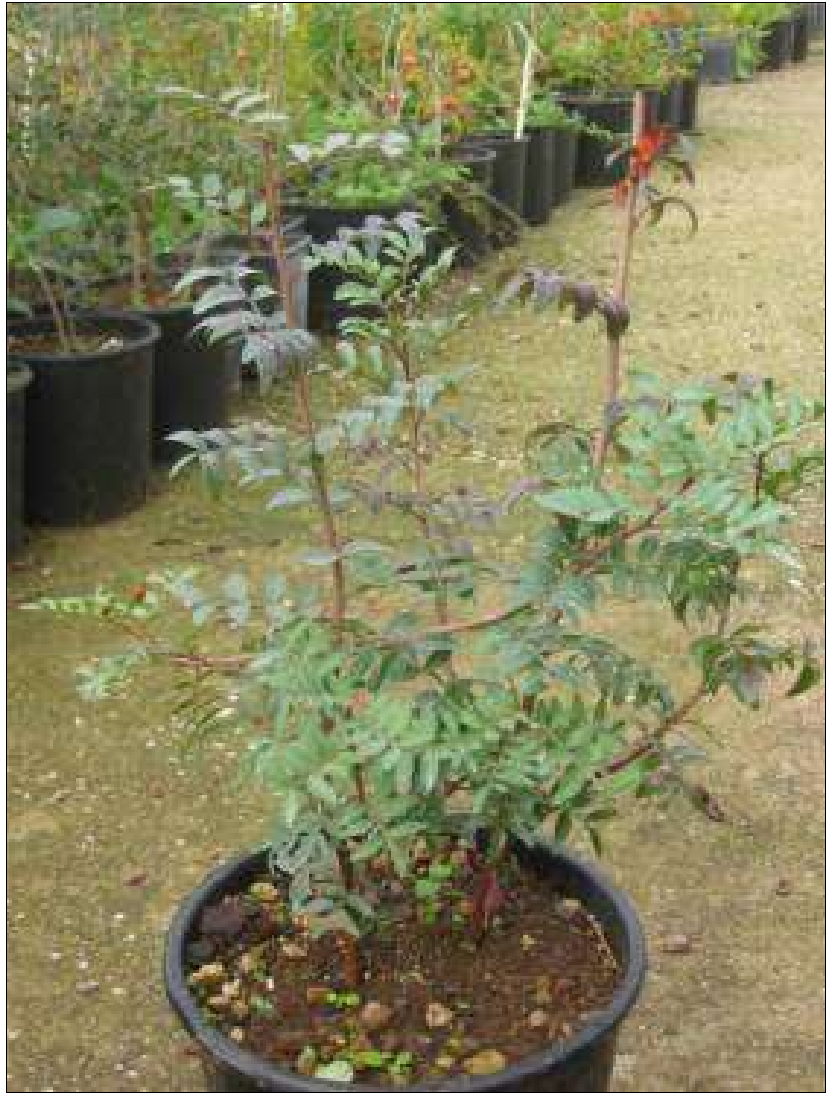

Fig. 1 - Rejuvenated donor plant of Pistacia lentiscus.

peatedly confirmed that auxin is required for initiation of adventitious roots on stems and that the development of the first initial root cells is dependent upon either applied or endogenous auxin (Hartmann et al. 2002). Nevertheless, the response to auxin treatment is not universal (cuttings of some difficult-to-root species still root poorly after treatment with auxin). For general use, the treatment

Fig. 2 - Semi-hardwood cuttings of Arbutus unedo, Myrtus communis, Phillyrea latifolia, Pistacia lentiscus, and Viburnum tinus.

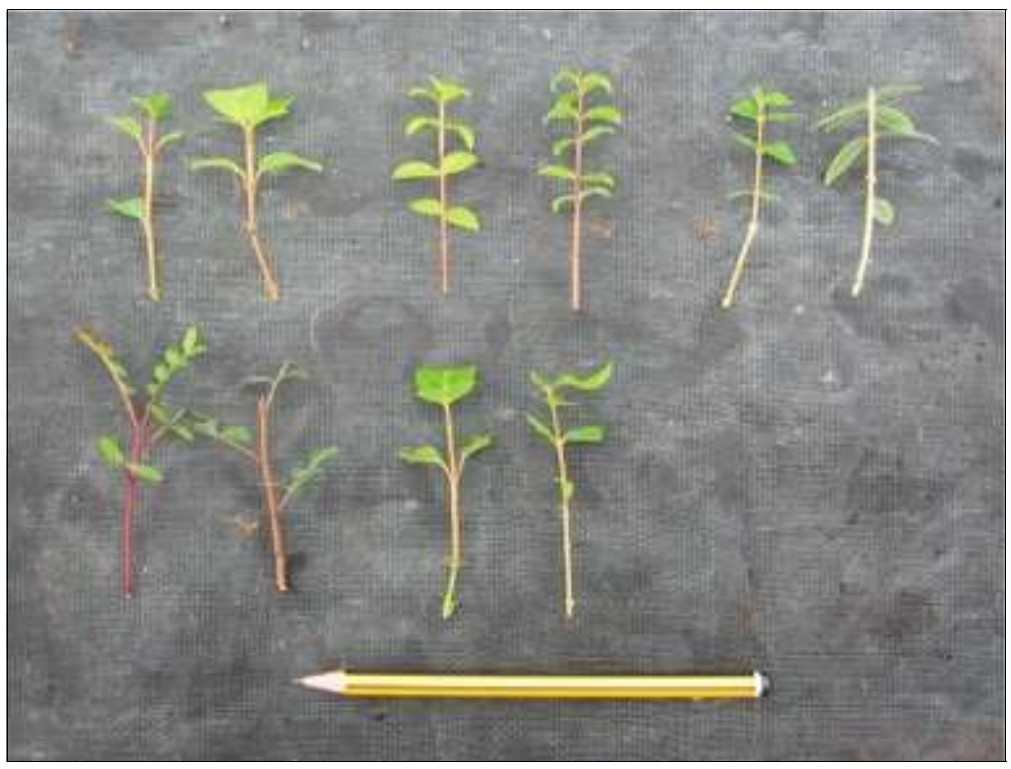


Effects of rejuvenation on cutting propagation of Mediterranean shrub species

Tab. 1 - Rooting probability (\%) for each combination of species, plant and material (mature plants: M, rejuvenated material: J). Graphical summary of the data in fig. 3.

\begin{tabular}{lcccc}
\hline \multirow{2}{*}{ Species } & \multicolumn{2}{c}{ April } & \multicolumn{2}{c}{ August } \\
\cline { 2 - 5 } & $\mathbf{M}$ & $\mathbf{J}$ & $\mathbf{M}$ & $\mathbf{J}$ \\
\hline Arbutus unedo & $0.0(0.0,9.7)$ & $44.4(27.9,61.9)$ & $16.7(6.4,32.8)$ & $50.0(32.9,67.1)$ \\
Laurus nobilis & $0.0(0.0,9.7)$ & $58.3(40.8,74.5)$ & $75.0(57.8,87.9)$ & $58.3(40.8,74.5)$ \\
Myrtus communis & $58.3(40.8,74.5)$ & $86.1(70.5,95.3)$ & $88.9(73.9,96.9)$ & $91.7(77.5,98.2)$ \\
Olea europaea v. & $66.7(49.0,81.4)$ & $100.0(90.3,100.0)$ & $11.1(3.1,26.1)$ & $100.0(90.3,100.0)$ \\
sylvestris & & & & \\
Phillyrea latifolia & $0.0(0.0,9.7)$ & $86.1(70.5,95.3)$ & $33.3(18.6,51)$ & $86.1(70.5,95.3)$ \\
Pistacia lentiscus & $0.0(0.0,9.7)$ & $22.2(10.1,39.2)$ & $0.0(0.0,9.7)$ & $77.8(60.8,89.9)$ \\
Viburnum tinus & $16.7(6.4,32.8)$ & $75.0(57.8,87.9)$ & $58.3(40.8,74.5)$ & $61.1(43.5,76.9)$ \\
\hline
\end{tabular}

with auxins (IBA and/or NAA) is recommended for the propagation of the majority of plant species (Davis \& Haissig 1990).

No randomization technique was adopted. For each species, one half of a container was arbitrarily assigned to $\mathrm{M}$ or $\mathrm{J}$ cuttings, and the disposition of the containers was chosen arbitrarily. Three months later, cuttings were gradually exposed to lower humidity reducing irrigation and opening the polyethylene protection foil, to induce hardiness in the rooted plants. After two weeks cuttings were individually checked to assess the presence of new adventitious roots.
Rooting probability was estimated for each species, material type, and period, using descriptive statistical techniques. The estimated rooting probability is reported together with exact binomial two-sided $95 \%$ confidence intervals.

\section{Results}

Rooting probability estimates and confidence intervals for each species, material type and period are shown in tab. 1, whereas fig. 3 provides a graphical summary of rooting probability.

Arbutus unedo rooting percentage for $\mathrm{M}$ cuttings was very low ( $0 \%$ in April, $16.7 \%$ in August, with

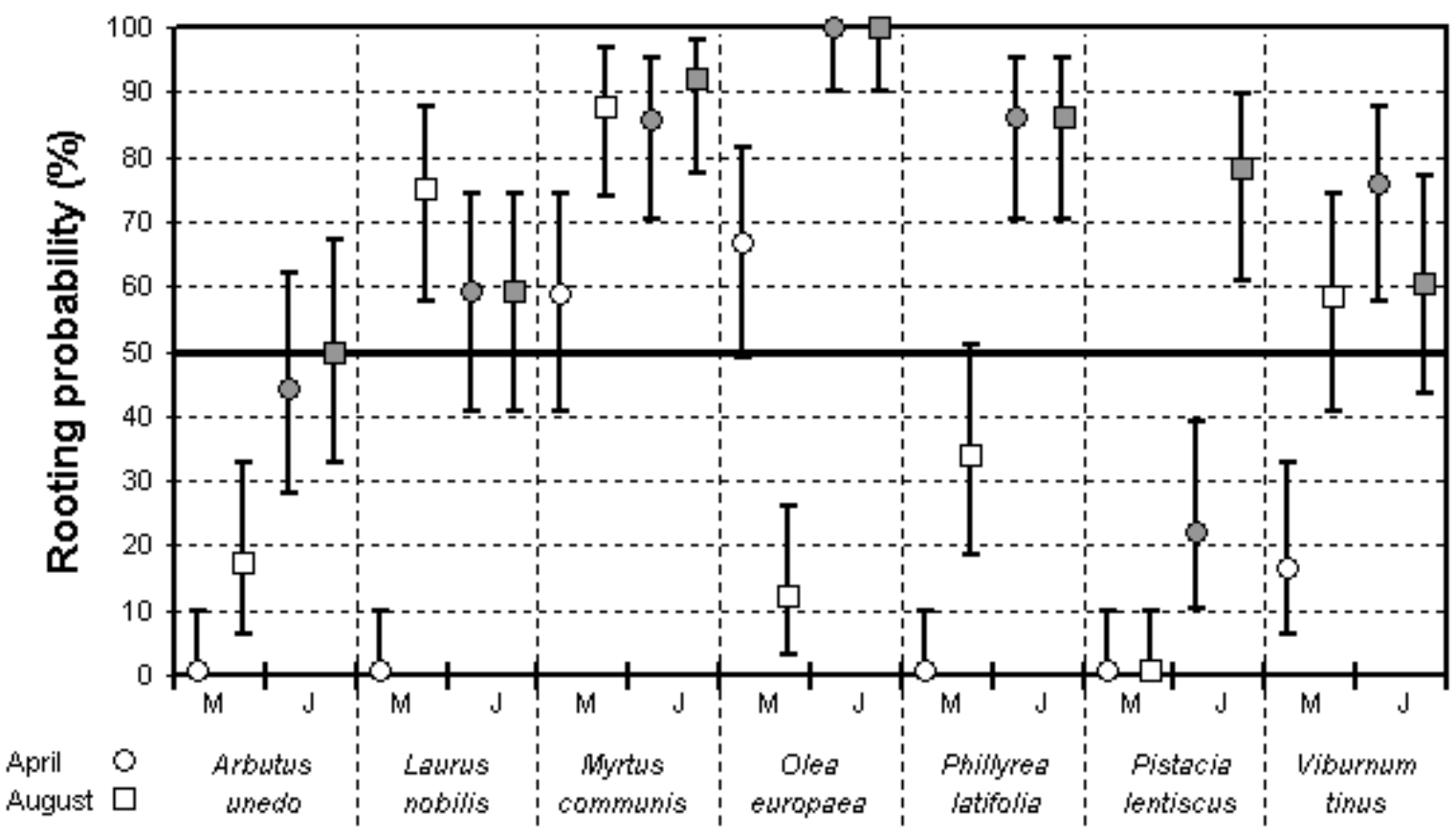

Fig. 3 - Rooting probability (\%), estimates and 95\% confidence intervals for each combination of species, plant and material. Point estimates for mature plants (M) are shown as white markers. Point estimates for rejuvenated material $(\mathrm{J})$, are shown in dark grey markers. 


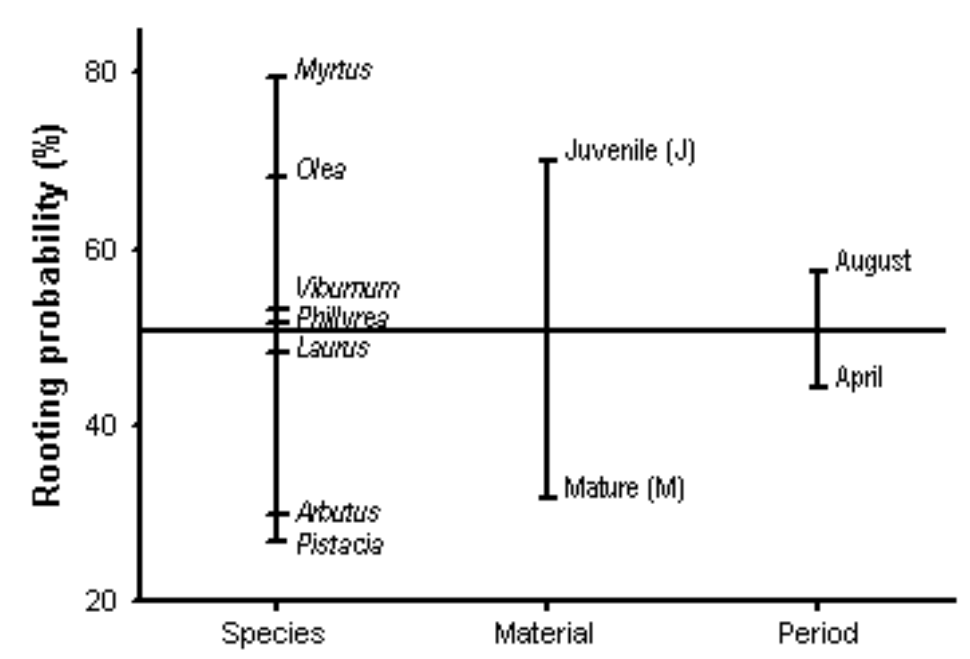

Fig. 4 - Estimated rooting probability (\%) by species (Arbutus unedo, Laurus nobilis, Myrtus communis, Olea europaea var. sylvestris, Phillyrea latifolia, Pistacia lentiscus and Viburnum tinus), material and period. confidence interval limits between 0.0 and $32.8 \%$ ), whereas J material performed better (44.4 and 50.0\% respectively, c.i. between 27.9 and $67.1 \%$ ). Myrtus communis M cuttings rooted well (58.3 and $88.9 \%$, c.i. between 40.8 and $96.9 \%$ ), and J cuttings gave even better results in both periods ( 86.1 and $91.7 \%$, c.i. between 70.5 and $98.2 \%$ ). Olea europaea var. sylvestris showed a similar trend: M cuttings (rooting 66.7 and $11.1 \%$, c.i. between 3.1 and $81.4 \%$ ) performed worse than J cuttings (rooting $100 \%$ in both periods, c.i between 90.3 and $100 \%$ ). Rooting of J cuttings of Phillyrea latifolia was markedly higher than M (86.1\% in both periods compared to 0 and $33.3 \%$ respectively; confidence interval limits were between 70.5 and 95.3\% compared to 0.0 and 51\%). Pistacia lentiscus M cuttings were the only ones not able to root whereas $\mathrm{J}$ cuttings rooted in April (22.2\%), and significantly more in August $(77.8 \%)$, with confidence interval between 10.1 and $89.9 \%$. Finally, also in Viburnum tinus, M cuttings (16.7 and 58.3\%, c.i. between 6.4 and $74.5 \%)$ rooted less than J (75.0 and $61.1 \%$, c.i. between 43.5 and $87.9 \%$ ). Laurus nobilis $\mathrm{M}$ cuttings were unable to root in April but $75.0 \%$ rooted in $\mathrm{Au}-$ gust (c.i. between 0 and $87.9 \%$ ) whereas $\mathrm{J}$ material rooted equally in the two periods $(58.3 \%$, c.i. between 40.8 and $74.5 \%$ ).

Estimated rooting probability by species, material or period, averaged across all other factors, is presented in fig. 4. For all species, except Laurus nobilis in the August test, the observed rooting probability was higher for J cuttings compared to M ones. Arbutus unedo and Pistacia lentiscus showed low rooting percentages in comparison to the other species. August was the best period for rooting for most species except for Laurus nobilis and Viburnum tinus.

\section{Discussion}

As already mentioned in the introduction, there are several techniques to rejuvenate forest species. The method we adopted for rejuvenating Mediterranean shrubs through rooted cuttings which in turn will produce new shoots for propagation material, could be considered as a cultural practice for producing stock plants.

Recent studies on vegetative propagation by cuttings of Mediterranean species doubted the possibility to develop protocols for difficult-to-root species, as Arbutus unedo, Pistacia lentiscus and Phillyrea latifolia, because of low and variable rooting success, strongly depending on the production period (Morini et al. 2003, La Viola et al. 2004). Our results with juvenile cuttings of these species, however, did not exclude reaching, and in some cases exceeding, 50\% rooting. This percentage is considered the threshold value of economic convenience for mass production in nurseries (Hartmann et al. 2002). The effect was consistent between the two periods. In any case, to avoid rooting failures typical for mature plants material $(0 \%)$, the use of cuttings collected from rejuvenated plants seemed to be of crucial importance.

For Viburnum tinus and Laurus nobilis, species with generally minor cutting propagation concerns, rooting percentages for rejuvenated materials were higher than $50 \%$. Finally, Myrtus communis and Olea europaea, as reported in the above mentioned studies, are suitable for mass production by cuttings in nurseries, but our observations showed that best performances were recorded for juvenile material. In Myrtus communis the differences between the two types of material seemed less important than in Olea.

The main findings of our research are consistent 
with several studies on forest species, which reported that juvenile tissues developed adventitious roots more easily (Bonga 1982, Maleike 1990, Sommer 1992). It is supposed that in the transition from juvenile to mature phase, specific genes are turned on or off and can negatively influence rooting since certain enzymes may or may not be produced (Davies 1993). Nevertheless the primary control of rooting is still unclear (Heuser \& Witham 1993, Hartmann et al. 2002).

In our study, the period of rooting seemed to be important for rooting success, although this was less relevant for juvenile cuttings. For mature materials, best results could be obtained in mid-late summer, when in Mediterranean climate a second period of growth starts with the first storm rains of August. For juvenile cuttings this effect seemed to be less important, maybe because donor plants were grown in the glasshouse, in more homogeneous environmental conditions. This difference in growing conditions of donor plants could bias to some extent the results of the study. Research has shown that the inherent rooting potential of shoots can be raised by treatments applied to stock plants, i.e. by general or localized dark treatment or by maintaining stock plants under a high carbohydrate/high nitrogen level. Although Heide (1968) evidenced a complex interaction between temperature and stock plant photoperiod on the level of endogenous auxins and other hormones, the effects of the air temperature on stock plants appears to play a minor role in the ease of rooting of cuttings (Hartmann et al. 2002). Nevertheless, the evaluation of different growing conditions of donor plants could be the aim of further research.

The exploratory nature of our study must be underlined. The study was carried out on a limited range of genotypes and on a total number of 48 cuttings for material/species. Further research is needed to investigate the relevance of the genotype factor, which may play a crucial role for propagation success because of the high variety of ecotypes in Mediterranean ecosystems.

\section{Conclusion}

The study underlined relevance of juvenile material for rooting success in propagation by cuttings of Mediterranean shrub species. The more interesting consequences, from the view point of nursery industry, were related to species, as Arbutus unedo and Pistacia lentiscus which are often difficult to propagate even by seed. A better definition of mass proto- cols by using juvenile plant stock material, the use of different growth regulators and the clarification of the role of genotype factor seems to be a priority for further research.

\section{References}

Bonga JM (1982). Vegetative propagation in relation to juvenility, maturity, and rejuvenation. In: Tissue culture in Forestry (Bonga JM, Durzan DJ eds), Nijhoff/Junk, The Hague, pp. 387-411.

Cervelli C, De Lucia B (2004). Floricoltura, vivaismo e arredo verde: gli usi ornamentali delle piante della macchia mediterranea. Italus Hortus, 11 (4): 40-49.

Davies FT (1983). Influence of juvenility and maturity in propagation. Comb. Proc. Intern. Plant Propag. Soc., 33: 559-564.

Davis TD, Haissig BE (1990). Chemical control of adventitious root formation in cuttings. Plant Growth Reg. Soc. Amer. Quart., 18 (1): 1-17.

Davies FT (1993). What's new in the biology of adventitious root formation. Comb. Proc. Intern. Plant Propag. Soc., 43: 382-385.

Deidda P, Mulas M (2004). La coltivazione e la valenza polifunzionale delle piante mediterranee. Italus Hortus, 11 (4): 31- 36.

Frangi P, Nicola S (2004). Studio della propagazione per talea di specie mediterranee di interesse ornamentale. Italus Hortus, 11 (4): 191-193.

Frau A, Cadinu M, Repetto A, Zedda A (2001). Micropropagazione di cinque cloni di mirto sardo. Informatore Agrario, 57 (17): 65-67.

Greenwood MS (1987). Rejuvenation of forest trees. J. Plant Growth Regulation 6 (1-2): 1-12.

Heide OM (1968). Auxin level and regeneration of Begonia leaves. Planta 81: 153-159.

Hartmann HT, Kester D, Davies F, Geneve R (2002). Plant Propagation, 7th edition. Upper Saddle River NJ, Prentice \& Hall.

Heuser CW, Witham F (1993). Adventitious root initiation - Future research on the site of auxin action. Comb. Proc. Intern. Plant Propag. Soc. 43: 521-525.

La Viola F, Forleo LR, Cocozza Talia MA (2004). Propagazione agamica di alcune specie della macchia mediterranea. Italus Hortus, 11 (4): 186-190.

Maleike R (1990). Some factors affecting rooting of cuttings. Comb. Proc. Intern. Plant Propag. Soc. 40: 191-194.

Mereti M, Grigoriadou K, Nanos GD (2002). Micropropagation of the strawberry tree, Arbutus unedo L. Scientia Horticulturae, 93 (2): 143-148.

Morgan DL, McWilliams EL, Parr WC (1980). Mantaining juvenility in live oak. HortScience 15: 493-494. 
Morini S, Fiaschi G (2000). In vitro propagation of strawberry tree. Agricoltura Mediterranea, 130 (3-4): 240-246

Morini S, Fiaschi G, D'Onofrio C (2003). Indagini sulla propagazione per talea di alcune specie arbustive della macchia mediterranea. Italus Hortus, 10 (6): 52-59.

Nobre J, Santos C, Romano A (2000). Micropropagation of the Mediterranean species Viburnum tinus. Plant Cell, Tis- sue and Organ Culture 60 (1): 75-78.

Siniscalco C, Pavolettoni L (1988). Rejuvenation of Eucalyptus $x$ trabutii by successive grafting. Acta Hort., 227: 98100 .

Sommer L (1992). The influence of juvenility on plant propagation. Comb. Proc. Intern. Plant Propag. Soc. 42: 175-176. 